\title{
Gêneros discursivos e autenticidade textual no ensino de língua estrangeira: uma análise de livros didáticos
}

\author{
Gislaine Machado Jerônimo \\ Letícia da Silva Barboza \\ Kelli da Rosa Ribeiro
}

Submetido em 05 de novembro de 2012.

Aceito para publicação em 18 de abril de 2013.

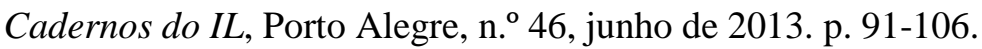

\section{POLÍTICA DE DIREITO AUTORAL}

Autores que publicam nesta revista concordam com os seguintes termos:

(a) Os autores mantêm os direitos autorais e concedem à revista o direito de primeira publicação, com o trabalho simultaneamente licenciado sob a Creative Commons Attribution License, permitindo o compartilhamento do trabalho com reconhecimento da autoria do trabalho e publicação inicial nesta revista.

(b) Os autores têm autorização para assumir contratos adicionais separadamente, para distribuição não exclusiva da versão do trabalho publicada nesta revista (ex.: publicar em repositório institucional ou como capítulo de livro), com reconhecimento de autoria e publicação inicial nesta revista.

(c) Os autores têm permissão e são estimulados a publicar e distribuir seu trabalho online (ex.: em repositórios institucionais ou na sua página pessoal) a qualquer ponto antes ou durante o processo editorial, já que isso pode gerar alterações produtivas, bem como aumentar o impacto e a citação do trabalho publicado.

(d) Os autores estão conscientes de que a revista não se responsabiliza pela solicitação ou pelo pagamento de direitos autorais referentes às imagens incorporadas ao artigo. A obtenção de autorização para a publicação de imagens, de autoria do próprio autor do artigo ou de terceiros, é de responsabilidade do autor. Por esta razão, para todos os artigos que contenham imagens, o autor deve ter uma autorização do uso da imagem, sem qualquer ônus financeiro para os Cadernos do IL.

\section{POLÍTICA DE ACESSO LIVRE}

Esta revista oferece acesso livre imediato ao seu conteúdo, seguindo o princípio de que disponibilizar gratuitamente o conhecimento científico ao público proporciona sua democratização.

http://seer.ufrgs.br/cadernosdoil/index

Sexta-feira, 14 de junho de 2013 


\title{
GÊNEROS DISCURSIVOS E AUTENTICIDADE TEXTUAL NO ENSINO DE LÍNGUA ESTRANGEIRA: UMA ANÁLISE DE LIVROS DIDÁTICOS
}

\author{
Gislaine Machado Jerônimo ${ }^{1}$ \\ Letícia da Silva Barboza ${ }^{2}$ \\ Kelli da Rosa Ribeiro ${ }^{3}$
}

\begin{abstract}
RESUMO: Escolher um material didático adequado às reais necessidades dos educandos é um dos temas mais importantes e, ao mesmo tempo, um dos maiores desafios para os professores de Língua Estrangeira (LE). No que tange ao processo de ensino e aprendizagem de língua estrangeira, destacamos dois aspectos: a autenticidade dos textos e a diversidade de gêneros discursivos. Para discutirmos sobre esses elementos, elegemos quatro coleções de livros didáticos, editadas a partir do ano de 2004; duas delas compreendem coleções de livros produzidos no Brasil, enquanto que outras duas contemplam um material elaborado em países que têm o inglês como língua materna. A ênfase da análise se dá nas unidades dos livros que apresentam os seguintes tempos verbais: presente, passado e futuro. A abordagem utilizada aqui é a dialógica bakhtiniana, a qual consiste em observar os enunciados na materialidade de um gênero discursivo. Com esse trabalho, pretendemos promover uma discussão sobre os tópicos abordados, bem como fornecer subsídios para o ensino/aprendizagem de LE.
\end{abstract}

PALAVRAS-CHAVE: ensino de língua estrangeira; gênero discursivo; autenticidade textual.

\section{INTRODUÇÃO}

O processo de ensino/aprendizagem de língua estrangeira, sem dúvida, tem se tornado alvo de muitos debates acadêmicos, sendo tema de pesquisas em variadas abordagens teóricas. Isso se deve ao papel importante que o acesso a uma língua estrangeira ocupa nas interações da sociedade globalizada. Nesse sentido, este artigo pretende levantar reflexões a respeito do ensino de língua estrangeira, voltando o olhar para o livro didático, um dos maiores aliados do professor nesse processo.

Desse modo, selecionamos quatro coleções de livros didáticos, utilizados em universidades, cursos de idioma ou escolas públicas. Tais livros foram editados a partir do ano de 2004, sendo que duas destas edições compreendem coleções de livros produzidos no Brasil. As outras duas edições contemplam um material elaborado em países que têm o inglês como língua materna. A partir desse material, buscamos analisar dois tópicos de suma importância para um ensino eficaz de língua estrangeira: a autenticidade textual e a diversidade de gêneros discursivos. Observaremos,

\footnotetext{
1 Doutoranda em Linguística pelo Programa de Pós-Graduação em Letras da Pontifícia Universidade Católica do Rio Grande do Sul (PUCRS). Bolsista CNPq. E-mail: gisa.jeronimo@ig.com.br 2 Mestranda em Linguística pelo Programa de Pós-Graduação em Letras da Pontifícia Universidade Católica do Rio Grande do Sul (PUCRS). Bolsista CAPES. E-mail: leticiabarboza1 @ hotmail.com 3 Doutoranda em Linguística pelo Programa de Pós-Graduação em Letras da Pontifícia Universidade Católica do Rio Grande do Sul (PUCRS). Bolsista CNPq. E-mail: ribeirokelli@ yahoo.com.br
} 
especificamente, se esses tópicos são contemplados e trabalhados nas unidades previamente selecionadas das coleções.

As reflexões levantadas neste trabalho são embasadas nas concepções dialógicas de linguagem, desenvolvidas por M. Bakhtin e seu Círculo. Tal abordagem explica a linguagem sob um ponto de vista enunciativo e dialógico, partindo-se do princípio de que os discursos são produzidos em momentos sócio-históricos concretos por sujeitos situados em momentos sócio-histórico diversos. Esses sujeitos mobilizam então a língua por meio de gêneros do discurso que organizam as variadas atividades sociais.

Assim, este artigo está organizado em três seções seguidas das considerações finais. Na primeira seção, apresentamos o referencial teórico de base para as discussões. Esta seção se divide ainda em quatro subseções: na subseção 1.1, abordamos questões concernentes ao ensino de língua estrangeira no Brasil; na subseção 1.2, discutimos o uso do livro didático no ensino de língua estrangeira; na subseção 1.3, trazemos a teoria bakhtiniana para desenvolver reflexões sobre os gêneros do discurso no livro didático de língua estrangeira; na subseção 1.4, falamos a respeito da autenticidade dos textos no livro didático.

Na segunda seção, expomos os procedimentos metodológicos. Essa seção está dividida em duas subseções: a subseção 2.1 faz uma caracterização dos livros didáticos brasileiros e também apresenta a análise das seções de leitura; a subseção 2.2 caracteriza os livros didáticos estrangeiros e analisa as seções de leitura. A terceira seção discute os dados analisados na metodologia. Por fim, nas considerações finais, concluímos nossa reflexão a respeito do ensino de língua estrangeira por meio dos textos em livros didáticos, deixando espaço para futuras discussões em pesquisas que tragam contribuições para este debate.

\section{REFERENCIAL TEÓRICO}

\subsection{O ensino de língua estrangeira em nosso país}

A necessidade de se aprender uma língua estrangeira é uma realidade que cresce cada vez mais em nosso país. Isso se deve a inúmeras razões que vão desde o desejo pessoal às exigências de um mundo globalizado. Os avanços científicos e tecnológicos permitem aos indivíduos o contato com outras nações de forma rápida e a cada dia mais frequente, o que vem a justificar a busca pelo aprendizado de outro idioma.

Entretanto, esse aprendizado, além de romper com as barreiras geográficas, aproximando pessoas e permitindo que elas interajam entre si, contribui para o autoconhecimento, a autopercepção e o papel do ser humano como cidadão. Dessa forma, podemos ressaltar que aprender um novo idioma vai além do desenvolvimento de habilidades linguísticas e comunicativas nessa língua, pois o contato com uma língua estrangeira possibilita ao indivíduo aprender mais sobre si, sobre o seu povo, seus valores, sua cultura e a forma de organização política e social da sociedade em que vive.

Além disso, saber outro idioma ultrapassa o acesso às informações linguísticas de uma língua especifica, pois permite que os aprendizes adquiram habilidades comunicativas dentro de sua língua materna e aprimorem o seu discurso de modo a se tornar um sujeito participante em seu meio. Esse caráter sociointeracionista da linguagem e da aprendizagem traz o desenvolvimento da consciência crítica do aluno sobre a sua linguagem e sobre a comunidade onde essa é utilizada. 
De acordo com os Parâmetros Curriculares Nacionais (PCNs), que norteiam a aprendizagem em nosso país, ao estudar uma língua estrangeira, o aluno conhece novas culturas, mas, primordialmente, desenvolve-se como ser humano, o que é um dos objetivos da disciplina.

\begin{abstract}
A aprendizagem de Língua Estrangeira no ensino fundamental não é só um exercício intelectual em aprendizagem de formas e estruturas linguísticas em um código diferente; é, sim, uma experiência de vida, pois amplia as possibilidades de se agir discursivamente no mundo. $\mathrm{O}$ papel educacional da Língua Estrangeira é importante, desse modo, para o desenvolvimento integral do indivíduo, devendo seu ensino proporcionar ao aluno essa nova experiência de vida. Experiência que deveria significar uma abertura para o mundo, tanto o mundo próximo, fora de si mesmo, quanto o mundo distante, em outras culturas. Assim, contribui-se para a construção, e para o cultivo pelo aluno, de uma competência não só no uso de línguas estrangeiras, mas também na compreensão de outras culturas. (BRASIL, 1998, p. 38)
\end{abstract}

Dessa maneira, conforme já mencionado, a aprendizagem de um idioma possibilita muito mais do que o desenvolvimento da competência linguística. Aprender uma língua estrangeira viabiliza oportunidades de expansão do saber científico e tecnológico e o acesso ao conhecimento em outras áreas, como turística, artística, comercial. Assim, seu estudo pode ser ministrado juntamente com outras disciplinas, como história, geografia, ciências físicas e biológicas, música etc.

O ensino de um idioma pressupõe a utilização dos conhecimentos adquiridos na vida pessoal, acadêmica e profissional, qualificando o aprendiz para a compreensão da sua cultura e a de outros povos, integrando-o a um mundo globalizado através da informação e da comunicação. Somente fazendo essa interação entre os conhecimentos transmitidos em sala de aula e a utilização deles no cotidiano é que se pode considerar a aprendizagem de uma língua estrangeira significativa para o educando.

\title{
2.2. O uso do livro didático no ensino de uma língua estrangeira
}

$\mathrm{Na}$ década de 70, o foco de aprendizagem de línguas deixou de ser apenas as habilidades linguísticas, contemplando também os aspectos comunicativos e a interação social. Isso veio a refletir nos materiais pedagógicos utilizados pelo professor em sala de aula. Dessa forma, o livro didático teve que ser adaptado a essa realidade, a fim de oferecer conteúdos sistemáticos e uma variedade de recursos para apresentar a língua estrangeira de forma que possibilitasse aos aprendizes utilizá-la para diversos fins.

Desde esse período, o livro didático (LD) passou a ser considerado como uma ferramenta valiosa para o professor. Seu uso aproxima os aprendizes de seu objeto de estudo tanto no aspecto linguístico quanto no comunicativo e sociocultural, uma vez que, ao se estudar uma LE, é extremamente importante considerar os falantes desse idioma, bem como as condições socioculturais desse grupo. Através do LD, os aprendizes terão acesso a essas informações e assim poderão realmente compreender e interessar-se pela língua-alvo. Além disso, o aluno poderá reconhecer a sua própria cultura, valorizando-a. É fundamental nesse aprendizado que o indivíduo perceba-se inserido em uma sociedade e que esta faz parte de um contexto ainda maior, o que vem a justificar a necessidade de se aprender uma língua estrangeira. 
Quanto ao ensino dos aspectos da língua, há materiais didáticos que englobam as quatro habilidades linguísticas: ler, falar, ouvir e escrever, bem como aqueles que focam em uma ou outra habilidade. Na maior parte dos materiais didáticos destinados à educação básica, o que inclui tanto instituições públicas como privadas de nosso país, percebemos que a ênfase é dada à leitura. Isso ocorre pois os PCNs (Brasil, 1998) sugerem que se promova o desenvolvimento dessa habilidade nas aulas de língua estrangeira, uma vez que o aprendiz amplia seu vocabulário e conhece a estrutura da língua, podendo assim obter uma compreensão geral de como esta se organiza.

Segundo Santos e Tomitch (2009), a leitura é um instrumento de busca de novos conhecimentos e novas perspectivas para os alunos. Devido a isso, as autoras destacam o importante papel da compreensão leitora e a apontam como o principal objetivo na aula de língua inglesa. Ainda, de acordo com as autoras, a leitura pode contribuir para o ensino das outras habilidades linguísticas, servindo como um fio condutor. O léxico e outros aspectos gramaticais da língua-alvo podem ser trabalhados a partir da leitura de um texto.

Susan Holden (2009) também menciona a importância de uma abordagem pedagógica voltada à leitura. Entretanto, para a autora, essa habilidade é fundamental, mas não a única. Atividades que contemplem a fala, a escrita e a audição também devem estar presentes no material didático utilizado pelo professor. Além disso, um bom recurso pedagógico é aquele que, além de considerar o desenvolvimento das habilidades comunicativas, explora o meio em que o aluno está inserido e permite a interação entre este e as diferentes populações que utilizam a língua estrangeira estudada.

Evidentemente que essas reflexões sobre leitura e ensino precisam estar pautadas por uma visão sociointeracional do processo de ler um texto. Segundo Leffa (1999), se considerarmos que a leitura não é só um processo cognitivo, mas que durante todo o processo há a presença marcante do outro, inevitavelmente precisaremos redimensionar o foco de uma visão de leitura centrada no indivíduo para uma visão de leitura dentro de um paradigma social em que os sentidos se constroem no processo de interação leitor texto - interlocutor - contexto social. Acreditamos assim que a leitura faz parte de um processo dialógico e dinâmico de construção de sentidos do texto, de modo que ela se inscreve como uma prática social nas diversas situações vivenciadas pelos sujeitos.

A escolha do livro didático é fundamental nesse processo. É necessário que o livro reflita as necessidades concretas dos educandos, a fim de auxiliá-los em seu processo de aprendizagem. Assim, é de suma importância que o professor conheça seus alunos, seus anseios, expectativas e objetivos referentes à aprendizagem da língua estrangeira. Para tanto, alguns critérios de avaliação para a escolha desse material que será utilizado em sala de aula devem ser estabelecidos, visando às características do grupo de alunos.

Apesar de seu caráter de legitimidade, bem como o de uma ferramenta facilitadora da aprendizagem, o livro didático é um dos diversos materiais que podem ser utilizados, mas não deve ser o único. Cabe ao professor selecionar aquilo de mais relevante que o livro didático traz, juntamente com outras fontes de saber. Vale ainda ressaltar que, embora reconhecida a sua importância, esse recurso pedagógico não pode substituir o papel do professor, isto é, o material didático é aliado de professores e alunos no processo de ensino/aprendizagem.

Consoante a essa discussão da importância do LD, bem como dos novos rumos e diretrizes do ensino de língua estrangeira e ainda do papel da leitura como habilidade linguística a ser enfatizada em sala de aula, não podemos deixar de fora algumas 
considerações sobre o estudo dos gêneros discursivos. No ensino da leitura em língua estrangeira e na composição do $\mathrm{LD}$, os gêneros passam a ter papel fundamental, uma vez que ajudam o aprendiz a aprender e a consolidar os diferentes tipos de textos. $\mathrm{Na}$ seção que segue, abordaremos os gêneros do discurso, estabelecendo relações entre os mesmos, o livro didático e o ensino de língua estrangeira.

2.3 Gêneros do discurso: questões teóricas a respeito do livro didático no ensino de uma língua estrangeira

Nas últimas décadas, as reflexões teóricas feitas sobre gêneros do discurso nos campos da linguística e dos estudos enunciativos proporcionaram novos pontos de vista a respeito da linguagem e do ensino de línguas na escola. De modo geral, é por meio de gêneros que interagimos socialmente e tomamos posição frente às diversas situações sócio-verbais das esferas do cotidiano. Assim, os gêneros do discurso se engendram e constituem nossas experiências e nossas relações com o outro. Tal perspectiva é baseada principalmente nas reflexões filosóficas e linguísticas desenvolvidas pelo pensador russo M. Bakhtin e seu Círculo.

No texto O problema dos gêneros do discurso, Bakhtin (2003, p. 262) afirma que "cada campo de utilização da língua elabora seus tipos relativamente estáveis de enunciados", os quais são intrinsecamente ligados às diversas atividades sociais. O autor ainda explica que um gênero é constituído de três elementos fundamentais: estilo, conteúdo e forma composicional. Esses elementos são produzidos e circulam numa determinada esfera de atividade humana, as quais são dinâmicas e diversificadas. Em nossa sociedade, podemos identificar claramente algumas dessas esferas, como por exemplo, esfera acadêmica e/ou pedagógica, midiática, jurídica, religiosa, jornalística, artística, política etc.

Interessante notar que é o estilo um dos principais elementos responsáveis pela relativa estabilidade do gênero do discurso, uma vez que se instaura uma relação de tensão entre o que é estável e repetível (a forma composicional) e o irrepetível, único e singular, ligado a um sujeito inserido num contexto sócio-histórico (estilo). Assim, o estilo é a marca da própria subjetivação e singularização do sujeito no enunciado, o qual faz parte de uma cadeia ativa e responsiva de comunicação social.

Os gêneros têm natureza dinâmica e vivem numa corrente ininterrupta de dinamicidade e elaboração de outros gêneros. Nesse sentido, os enunciados pertencentes aos variados gêneros do discurso reverberam relações dialógicas com outros enunciados de outros gêneros e também de outras esferas discursivas. Assim, Bakhtin afirma que

[...] a riqueza e a diversidade dos gêneros do discurso são infinitas porque são inesgotáveis as possibilidades da multiforme atividade humana e porque em cada campo dessa atividade é integral o repertório de gêneros do discurso, que cresce e se diferencia à medida que se desenvolve e se complexifica um determinado campo (BAKHTIN, 2003, p. 262).

Dessa forma, são também inesgotáveis as relações de diálogo entre gêneros e entre esferas. Tais diálogos tornam os enunciados e suas esferas mais complexas, e esse processo pode se refletir na própria forma composicional do gênero do discurso, 
dependendo é claro da maior ou menor plasticidade desse gênero. Cabe salientar que, quando Bakhtin se refere à riqueza dos gêneros, está englobando todas as formas de discurso oral e escrito, desde os enunciados de uma simples conversa cotidiana com pessoas íntimas ou diálogos mais formais como uma entrevista de emprego, até enunciados de documentos oficiais, textos religiosos ou solenidades diversas.

É importante compreender a estreita correlação que cada gênero estabelece com a situação concreta de comunicação e como esse gênero do discurso cumpre determinada função junto à comunidade linguística. Marcuschi (2008, p. 208) salienta que a produção discursiva em gêneros "tem como correlata a própria organização da sociedade, o que nos faz pensar no estudo sócio-histórico dos gêneros textuais como uma das maneiras de entender o próprio funcionamento social da língua". É por isso que Bakhtin (2003, p. 282) ressalta que nos comunicamos por meio dos gêneros e essas formas de comunicação são dadas aos falantes da mesma forma que a língua materna é dada, a qual dominamos livremente até começarmos o estudo teórico da gramática.

Assim, conforme Bakhtin, quanto melhor e mais eficientemente dominarmos os gêneros, melhor e com mais plena habilidade empregamos neles a nossa individualidade, realizando nosso projeto discursivo (BAKHTIN, 2003, p. 285). Nessa direção, consideramos de suma importância vincular o processo de ensino-aprendizagem de uma língua estrangeira a gêneros que se produzam, circulem e sejam recebidos em diferentes esferas da comunicação social, uma vez que o gênero é intrinsecamente ligado à atividade humana. Ou seja, percebemos vários e heterogêneos gêneros discursivos nos diferentes campos de confluência dos discursos pelo fato de também serem as atividades humanas heterogêneas, complexas e, principalmente, dinâmicas.

Levando em consideração tais questões e a realidade de várias escolas brasileiras, as quais têm por base, muitas vezes, o livro didático, entendemos que algumas reflexões precisam ser levantadas a respeito desse importante material didático que compreende vários gêneros na esfera pedagógica/escolar. Aliás, é uma discussão importante considerar o livro didático de língua estrangeira como um gênero discursivo, visto que é um texto que se dirige a um público específico e desempenha funções sociais bem delimitadas. Segundo Bunzen e Rojo (2005), se assumirmos uma posição sócio-histórica de abordagem do livro didático, devemos compreender os diversos discursos sociais que emergem de redes intertextuais e interdiscursivas tecidas para a elaboração do que os autores chamam de projeto didático autoral. Assim, podemos afirmar que o livro didático de língua estrangeira enquanto gênero discursivo contém todos os elementos essenciais para ser classificado como tal, tendo em vista a visão bakhtiniana. Desse modo, o livro didático de língua estrangeira, de maneira geral, possui:

a) um projeto discursivo, um estilo: editores, pesquisadores, professores elaboram o material didático, estruturam as seções e unidades, fazem a distribuição dos conteúdos, selecionam outros gêneros que farão parte do livro;

b) uma estrutura relativamente repetível: há seções e unidades que tratam de aspectos gramaticais, enunciados que propõem as questões, os exercícios, outros gêneros discursivos, como notícias, receitas, charges etc.

c) conteúdo: os conteúdos científicos, didáticos, técnicos e culturais que envolvem a língua estrangeira;

d) função social: há a função de ensinar conteúdos que envolvem a aquisição de língua estrangeira, desenvolver habilidades de leitura e escrita, colocar o aluno em contato com os aspectos contextuais da língua, entre outras; 
d) interlocutor: professores e alunos;

e) vínculo estreito com a esfera discursiva pedagógicalescolar.

É importante ressaltar nessa perspectiva que uma das principais funções do livro didático, na esfera sócio-discursiva, é nortear o processo de ensino-aprendizagem de conteúdos escolares, tanto de língua materna quanto de língua estrangeira. Evidentemente, o público interlocutor desse suporte, bem como o dos gêneros discursivos engendrados no livro, são alunos e professores, pois esses sujeitos estão envolvidos diretamente no processo. Outro aspecto a ser destacado se refere à estrutura relativamente repetível do livro didático. O livro é tecido não só por unidades e seções que tratam dos conteúdos técnicos de ensino da língua estrangeira, mas nesse gênero há também a presença marcante de outros gêneros discursivos que se integram a essa rede interdiscursiva com finalidades didáticas. Assim, percebemos a complexidade que envolve a elaboração de um material que tem por essência a diversidade de vozes que estabelecem entre si relações de sentidos.

Nesse contexto, conforme Bentes (2005, p. 117), ao se elaborar um livro didático, as escolhas dos textos a serem integrados no gênero livro didático precisam levar em consideração três principais questões teóricas:

a) os gêneros são produtos coletivos e em constante processo de re-elaboração, que resultam de um trabalho sócio-histórico sobre/com a linguagem, trabalho este produzido por determinados agentes sociais no interior de esferas comunicacionais específicas;

b) os gêneros são produzidos em função de um determinado intuito-discursivo (um projeto de dizer);

c) os gêneros produzidos para certos interlocutores e/ou para uma comunidade de interlocutores.

Essa visão é essencial para a elaboração de manuais escolares de língua estrangeira, uma vez que o aprendiz de outra língua precisa se apropriar não só das formas gramaticais desse novo sistema aprendido, mas, sobretudo, ele necessita entrar em contato com os gêneros discursivos produzidos numa determinada língua. Apreender determinado gênero de uma língua estrangeira é apreender aspectos sócioculturais-históricos que envolvem essa língua. Além disso, as formas relativamente estáveis de comunicação que fazem parte dos manuais necessitam ter dois principais elementos: a fonte, que é o vínculo concreto do texto e seu contexto de produção, e a autoria, que é um aspecto fundamental que garante o estilo e a autenticidade dos textos.

Desse modo, proporcionar ao aluno o contato com diferentes gêneros é também oportunizar a aprendizagem de diversas atividades, formas de interação e relações sociais em geral. Assim, compreendemos que, ao dominar os gêneros e as atividades que a eles são diretamente vinculadas, os estudantes têm nas mãos o poder de estabelecer qualquer tipo de relação ao usar adequadamente o discurso e suas formas em variados contextos socioculturais. Indo mais além, se o aluno domina os gêneros de uma língua estrangeira, ele adentra com habilidade num universo estranho, descobrindo as multifacetas discursivas desse "outro" universo.

Ter domínio dos gêneros discursivos, portanto, é uma necessidade no contexto atual de ensino/aprendizagem de uma língua estrangeira. Mas, além de se ter domínio dos gêneros do discurso, há igualmente de se atentar à fonte do texto, assim como à autoria do mesmo. Ambos os elementos citados, juntamente com o gênero, estão interligados e garantem a autenticidade textual, aspecto fundamental a ser considerado. Na próxima seção, trataremos com mais detalhes do tema da autenticidade textual. 


\subsection{A autenticidade dos textos no livro didático e o ensino de língua estrangeira}

O ensino de língua estrangeira (ELE) frequentemente suscita alguns debates. Destacamos, principalmente, os relacionados ao trabalho com o texto em sala de aula. Mas anterior a isso, em um primeiro momento, abordaremos alguns fatores que contribuíram para o fortalecimento do trabalho com o texto autêntico, enquanto importante ferramenta no ELE.

A partir da década de 70, as abordagens comunicativas tomaram grande espaço no ELE e o intuito da aprendizagem passou a ser a comunicação e a interação social (MISHAN, 2005). Entretanto, para uma comunicação adequada, o aprendiz necessita contemplar os diferentes tipos de gêneros discursivos, pois ora ele precisa narrar uma história, ora precisa fazer a descrição de uma paisagem ou objeto, entre outras necessidades. Em tais comunicações, esse sujeito deve fazer uso de vocabulário adequado e de estruturas estáveis (gêneros) aos diversos contextos de uso da língua. Para tanto, ele necessita de modelos a serem seguidos. O contato com textos autênticos, por sua vez, oferece modelos de uso real aos aprendizes. Foi em meio a esse contexto que a autenticidade textual ganhou maior espaço nas pautas de discussão. Os elementos linguísticos presentes nos textos, nessa ótica, passaram a ser observados em conjunto com o gênero textual no qual estavam inseridos.

Nas décadas de 70 e 80, outra influência veio das abordagens humanísticas, as quais direcionavam a aprendizagem para o próprio sujeito, isto é, para o aprendiz e suas necessidades comunicativas (SCHUBERT, 2010). Dentre elas, estava a de compreender e produzir os mais variados gêneros do discurso.

Mais recentemente, o acesso a textos autênticos também se ampliou, devido ao advento da internet e da evolução das tecnologias de informação e comunicação que se tornaram mais acessíveis às pessoas (SCHUBERT, 2010).

Segundo Schubert (2010), o estouro do movimento pela autenticidade é provavelmente fruto dos movimentos referidos anteriormente. Cabe, no entanto, fazer o seguinte questionamento: o que seria um texto autêntico? A literatura nos traz diferentes definições, as quais, na maioria das vezes, não convergem. Na sequência, retomaremos essa questão.

Os educadores, preocupados com o êxito dos educandos no processo de ensino/aprendizagem, se indagam sobre que tipo de material didático se mostra mais adequado e eficiente no cotidiano da sala de aula. Em um âmbito mais especifico, no que tange ao texto, esses educadores igualmente se questionam sobre qual tipo de texto deve ser explorado para desenvolver a habilidade linguística de leitura - se "textos autênticos" (os de uso corrente) ou "textos não autênticos" (os criados apenas para o uso do livro didático).

O que entra em pauta nos debates e discussões de tais educadores é se textos produzidos, sobretudo para trabalhar algum tópico específico de gramática, por exemplo, atenderiam às necessidades dos educandos em termos de contato com um idioma "da vida real" (HOLDEN, 2009). E se questionam também se esse tipo de texto daria conta de desenvolver as habilidades e competências exigidas dos aprendizes.

Contudo, a dificuldade inicial está em se definir o que seja um texto autêntico, pois o mesmo pode, em algumas abordagens, ser considerado semiautêntico. Por exemplo, uma reportagem veiculada em uma revista que, posteriormente, tenha sido resumida ou adaptada para um livro didático. Nesse caso, haveria uma modificação do texto original para fins pedagógicos. De acordo com algumas opiniões, essa adaptação, 
por partir de um texto original, seria considerada um texto semiautêntico. No entanto, em outros pontos de vista, quando o texto sofre qualquer alteração, a fim de atender a uma necessidade pedagógica, o mesmo deixa de ser considerado como autêntico ou mesmo semiautêntico, passando a ser considerado como não autêntico.

Pensamos que o segundo ponto de vista, por se mostrar mais fiel ao texto original, seja mais relevante no dia a dia da sala de aula. Entretanto, não se trata de desqualificar o texto adaptado como um todo. Mas sim de enfatizar - por parte do educador - a necessidade de proporcionar ao aprendiz o contato e a exposição a materiais de uso real. Pensamos ainda que a adaptação não deva ser feita por meio do material didático, isto é, do texto - mas sim da forma, da metodologia de como esse texto vai ser trabalhado - para que ele dê as condições necessárias e seja um elemento auxiliar no trabalho do educador. Caso o texto escolhido não satisfaça as necessidades educacionais, que seja escolhido outro que melhor se enquadre. E, se por acaso, o tópico desejado não seja encontrado nos textos de uso corrente, seria, então, de se questionar a necessidade de se trabalhar com algum tópico tão desvinculado dos textos que se inserem no uso efetivo e nos mais variados veículos de comunicação.

$\mathrm{O}$ termo autêntico, assim, no contexto aqui empregado, significa um texto que tenha sido escrito para o mundo real (HOLDEN, 2009). Trata-se de um texto que envolva a língua viva e que seja veiculado nos diversos meios comunicativos, podendo se enquadrar em diferentes gêneros, como, por exemplo, música, propaganda, texto informativo, reportagem, charge, história em quadrinhos, entrevistas, entre inúmeros outros.

O educador necessita, além do já exposto, utilizar de critérios claros na escolha dos materiais didáticos. É importante - no que tange ao texto - escolher uma coleção que leve em conta os objetivos do curso, interesse e idade dos aprendizes, adequação ao nível linguístico dos alunos de LE e gêneros discursivos (SANTOS; TOMITCH, 2009).

A fim de contribuir com o debate aqui referido, na próxima seção, traremos dados referentes à análise de algumas coleções de livros didáticos de Língua Estrangeira, em especial, de Língua Inglesa. Segue, na seção 2, a metodologia utilizada no presente trabalho.

\section{METODOLOGIA}

Elegemos quatro coleções de livros didáticos (duas nacionais e duas internacionais) para a nossa análise. Nossa ênfase se dá nas unidades que, de acordo com nossa percepção enquanto professoras de língua inglesa, são as mais basilares dos livros em termos de estrutura gramatical. Fizemos, assim, um recorte do material e nos pautamos nas unidades que apresentam os tempos verbais do presente, passado e futuro. Analisamos, portanto, três unidades de cada coleção, as quais trazem os seguintes tempos verbais em inglês: simple present tense, simple past tense e future.

A abordagem aqui utilizada vai ao encontro da teoria dialógica bakhtiniana, a qual consiste em observar os enunciados na materialidade de um gênero discursivo. Desse modo, defendemos a necessidade de uso de textos autênticos e de gênero variado nos livros didáticos. Nas quatro coleções elegidas, examinamos, então, a autenticidade dos textos e a diversidade de gêneros discursivos. O que buscamos é verificar se esses livros didáticos contemplam tais tópicos e se há diferença entre as coleções de livros brasileiros e estrangeiros, no que tange a esses itens. 


\section{leitura \\ 3.1 Caracterização dos livros didáticos brasileiros e análise das seções de}

As duas coleções de livros didáticos brasileiros elegidas fazem parte do Plano Nacional de Livro Didático (PNLD) ${ }^{4}$. São elas: English for all, da editora Saraiva, e On stage, da editora Ática. A primeira delas será identificada como 'coleção de livro didático 1' (CLD1), e a segunda será identificada respectivamente como CLD2.

A CLD1 é composta por três volumes, um para cada série do Ensino Médio. Cada volume contém 10 unidades, e cada uma dessas 10 unidades possui um assunto central como enfoque. Há um sumário bem dividido e explicativo em cada livro sobre as partes que compõem o English for all. Em todas as unidades são abordadas as quatro habilidades linguísticas. A habilidade de leitura é trabalhada através de dois textos em cada unidade, os quais introduzem as temáticas a serem desenvolvidas. O primeiro texto abre, portanto, a unidade e, juntamente a ele, vêm questões de pré e pós-leitura. $\mathrm{O}$ segundo texto serve de modelo à atividade de escrita. Há uma relação de bastante coerência entre os textos e os tópicos gramaticais propostos. Quanto ao tópicos gramaticais de desejo, os localizamos em três unidades distintas: tempo verbal presente (unidade 4), tempo verbal passado (unidade 6) e tempo verbal futuro (unidade 10). Nas unidades analisadas, encontramos textos autênticos - com fonte bem definida -, diversidade de gênero e presença de elementos linguísticos e não linguísticos, conforme mostra o quadro abaixo (Quadro 1).

Quadro 1 - Análise das seções de leitura (unidades 4, 6 e 10) - coleção English for all -

CLD1

\begin{tabular}{|c|c|c|c|c|}
\hline UNIDADE & $\begin{array}{l}\text { TÓPICO } \\
\text { GRAMATICAL }\end{array}$ & $\begin{array}{l}\text { GÊNEROS } \\
\text { DISCURSIVOS } \\
\text { CONTEMPLADOS }\end{array}$ & $\begin{array}{l}\text { AUTENTICIDADE } \\
\text { TEXTUAL }\end{array}$ & $\begin{array}{l}\text { ASPECTOS } \\
\text { OBSERVADOS }\end{array}$ \\
\hline \multirow[b]{2}{*}{$\begin{array}{l}\text { Unidade } 4 \\
\text { Diferentes } \\
\text { Culturas }\end{array}$} & \multirow[b]{2}{*}{$\begin{array}{l}\text { Simple Present } \\
\text { Tense }\end{array}$} & $\begin{array}{l}\text { Texto 1: artigo } \\
\text { informativo }\end{array}$ & $\begin{array}{l}\text { Texto Autêntico } \\
\text { Fonte: revista - cita } \\
\text { nome e ano }\end{array}$ & $\begin{array}{l}\text { Presença de elementos } \\
\text { visuais facilitadores de } \\
\text { compreensão - fotografia }\end{array}$ \\
\hline & & $\begin{array}{l}\text { Texto 2: artigo } \\
\text { informativo }\end{array}$ & $\begin{array}{l}\text { Texto Autêntico } \\
\text { Fonte: página da } \\
\text { internet - com data de } \\
\text { acesso }\end{array}$ & $\begin{array}{l}\text { Presença de elementos } \\
\text { visuais facilitadores de } \\
\text { compreensão - página da } \\
\text { internet com plano de fundo }\end{array}$ \\
\hline \multirow{2}{*}{$\frac{\text { Unidade } 6}{P a z}$} & \multirow{2}{*}{$\begin{array}{l}\text { Simple Past } \\
\text { Tense }\end{array}$} & Texto 1: biografia & $\begin{array}{l}\text { Texto Autêntico } \\
\text { Fonte: página da } \\
\text { internet - com data de } \\
\text { acesso }\end{array}$ & $\begin{array}{l}\text { Presença de elementos } \\
\text { visuais facilitadores de } \\
\text { compreensão - fotografia }\end{array}$ \\
\hline & & $\begin{array}{l}\text { Texto 2: capas de } \\
\text { revistas }\end{array}$ & $\begin{array}{l}\text { Texto Autêntico } \\
\text { Fonte: revista }\end{array}$ & $\begin{array}{l}\text { Presença de elementos } \\
\text { linguísticos facilitadores de } \\
\text { compreensão - frase } \\
\text { explicativa das capas }\end{array}$ \\
\hline \multirow[t]{2}{*}{$\frac{\text { Unidade } 10}{\text { Viagem }}$} & \multirow[t]{2}{*}{ Future } & $\begin{array}{l}\text { Texto 1: artigo } \\
\text { informativo }\end{array}$ & $\begin{array}{l}\text { Texto Autêntico } \\
\text { Fonte: página da } \\
\text { internet - com data de } \\
\text { acesso }\end{array}$ & $\begin{array}{l}\text { Presença de elementos } \\
\text { visuais facilitadores de } \\
\text { compreensão - fotografia }\end{array}$ \\
\hline & & $\begin{array}{l}\text { Texto 2: artigo } \\
\text { informativo }\end{array}$ & $\begin{array}{l}\text { Texto Autêntico } \\
\text { Fonte: página da } \\
\text { internet - com data de } \\
\text { acesso }\end{array}$ & $\begin{array}{l}\text { Presença de elementos } \\
\text { visuais facilitadores de } \\
\text { compreensão - fotografia }\end{array}$ \\
\hline
\end{tabular}

4 O PNLD é um programa do Ministério da Educação, subsidiado pelo Fundo Nacional de Desenvolvimento da Educação, cujo objetivo é a distribuição de livros didáticos para escolas públicas de todo o país. 
A CLD2 apresenta as mesmas características iniciais da CLD1, porém os tópicos gramaticais não são exibidos em apenas uma unidade cada. O tempo verbal presente é trabalhado em três unidades distintas, pois em cada uma delas é abordada uma forma verbal (afirmativa, negativa e interrogativa). Já o tempo passado aparece em duas unidades, uma para a forma afirmativa e outra para as formas negativa e interrogativa. Apenas o tempo futuro permanece sendo abordado em uma única unidade. Desse modo, o CLD2 traz 6 unidades que se relacionam com os tópicos escolhidos.

O sumário de cada livro da coleção não é muito explicativo, pois - apenas por meio dele - não é possível entender a temática que será trabalhada nas unidades, nem o tipo de habilidade linguística a ser explorado. Os textos - em sua maioria - são adaptações, isto é, não autênticos. A fonte, muitas vezes, não traz informações completas, quando existe. Segue, no Quadro 2, maiores detalhes dos textos analisados dessa coleção.

Quadro 2 - Análise das seções de leitura (unidades 2,3,4, 5, 6 e 10) - coleção On stage - CLD2

\begin{tabular}{|c|c|c|c|c|}
\hline UNIDADE & $\begin{array}{l}\text { TÓPICO } \\
\text { GRAMATICAL }\end{array}$ & $\begin{array}{l}\text { GÊNEROS } \\
\text { DISCURSIVOS } \\
\text { CONTEMPLADOS }\end{array}$ & $\begin{array}{l}\text { AUTENTICIDADE } \\
\text { TEXTUAL }\end{array}$ & $\begin{array}{l}\text { ASPECTOS } \\
\text { OBSERVADOS }\end{array}$ \\
\hline \multirow{2}{*}{$\begin{array}{l}\frac{\text { Unidade } 2}{\text { Pinguins }} \\
\text { da } \\
\text { Antártida }\end{array}$} & \multirow{2}{*}{$\begin{array}{l}\text { Simple Present } \\
\text { Tense }\end{array}$} & Texto 1: reportagem & $\begin{array}{l}\text { Texto adaptado - menção } \\
\text { da fonte principal, com } \\
\text { mencão da data de acesso }\end{array}$ & $\begin{array}{l}\text { Presença de elementos } \\
\text { visuais facilitadores de } \\
\text { compreensão }\end{array}$ \\
\hline & & $\begin{array}{l}\text { Texto 2: misto } \\
\text { (fragmento de mapa, } \\
\text { foto e legenda) }\end{array}$ & $\begin{array}{l}\text { Texto adaptado - menção } \\
\text { da fonte, sem menção do } \\
\text { ano de publicação }\end{array}$ & $\begin{array}{l}\text { Presença de elementos } \\
\text { visuais facilitadores de } \\
\text { compreensão }\end{array}$ \\
\hline \multirow[t]{2}{*}{$\frac{\text { Unidade } 3}{\text { Poluição }}$} & \multirow[t]{2}{*}{$\begin{array}{l}\text { Simple Present } \\
\text { Tense }\end{array}$} & Texto 1: informativo & $\begin{array}{l}\text { Texto adaptado de uma } \\
\text { revista datada do ano de } \\
1985\end{array}$ & $\begin{array}{l}\text { Presença de elementos } \\
\text { visuais facilitadores de } \\
\text { compreensão; Fragmento } \\
\text { de texto muito antigo }\end{array}$ \\
\hline & & $\begin{array}{l}\text { Texto 2: artigo de } \\
\text { opinião }\end{array}$ & $\begin{array}{l}\text { Texto adaptado de uma } \\
\text { revista, sem menção do ano } \\
\text { de publicação }\end{array}$ & $\begin{array}{l}\text { Presença de elementos } \\
\text { visuais facilitadores de } \\
\text { compreensão - fotografia }\end{array}$ \\
\hline \multirow{2}{*}{$\begin{array}{l}\text { Unidade } 4 \\
\text { Mata } \\
\text { Atlântica }\end{array}$} & \multirow[t]{2}{*}{$\begin{array}{l}\text { Simple Present } \\
\text { Tense }\end{array}$} & Texto 1: reportagem & $\begin{array}{l}\text { Texto Autêntico } \\
\text { Fonte: página da internet - } \\
\text { com data de acesso }\end{array}$ & $\begin{array}{l}\text { Presença de elementos } \\
\text { visuais facilitadores de } \\
\text { compreensão - fotografia }\end{array}$ \\
\hline & & Texto 2: reportagem & $\begin{array}{l}\text { Texto Adaptado } \\
\text { Fonte: página da internet - } \\
\text { com data de acesso }\end{array}$ & $\begin{array}{l}\text { Presença de elementos } \\
\text { visuais facilitadores de } \\
\text { compreensão - fotografia }\end{array}$ \\
\hline \multirow{2}{*}{$\begin{array}{l}\text { Unidade } 5 \\
\text { Santos } \\
\text { Dumont }\end{array}$} & \multirow[t]{2}{*}{$\begin{array}{l}\text { Simple Past } \\
\text { Tense }\end{array}$} & Texto 1: biografia & $\begin{array}{l}\text { Texto Autêntico } \\
\text { Fonte: revista }\end{array}$ & $\begin{array}{l}\text { Presença de elementos } \\
\text { linguísticos facilitadores } \\
\text { de compreensão - } \\
\text { fotografia }\end{array}$ \\
\hline & & $\begin{array}{l}\text { Texto 2: fotografia e } \\
\text { legenda }\end{array}$ & Texto sem fonte & \\
\hline \multirow{2}{*}{$\frac{\text { Unidade } 6}{\text { Música }}$} & \multirow{2}{*}{$\begin{array}{l}\text { Simple Past } \\
\text { Tense }\end{array}$} & Texto 1: biografia & $\begin{array}{l}\text { Texto Adaptado } \\
\text { Fonte: página da internet - } \\
\text { com data de acesso }\end{array}$ & $\begin{array}{l}\text { Presença de elementos } \\
\text { visuais facilitadores de } \\
\text { compreensão - fotografia }\end{array}$ \\
\hline & & Texto 2: notícia & $\begin{array}{l}\text { Texto Adaptado } \\
\text { Fonte: página da internet - } \\
\text { com data de acesso }\end{array}$ & $\begin{array}{l}\text { Presença de elementos } \\
\text { visuais facilitadores de } \\
\text { compreensão - fotografia }\end{array}$ \\
\hline \multirow{2}{*}{$\frac{\text { Unidade } 10}{V i d a}$} & \multirow[t]{2}{*}{ Future } & Texto 1: reportagem & $\begin{array}{l}\text { Texto Adaptado } \\
\text { Fonte: página da internet - } \\
\text { sem data de acesso }\end{array}$ & $\begin{array}{l}\text { Presença de elementos } \\
\text { visuais facilitadores de } \\
\text { compreensão - fotografia } \\
\end{array}$ \\
\hline & & $\begin{array}{l}\text { Texto 2: fotografia e } \\
\text { legenda }\end{array}$ & Texto sem fonte & $\begin{array}{l}\text { Presença de elementos } \\
\text { visuais facilitadores de } \\
\text { compreensão - fotografia }\end{array}$ \\
\hline
\end{tabular}




\subsection{Caracterização dos livros didáticos estrangeiros e análise das seções de leitura}

As coleções de livros internacionais analisadas são Interchange e Touchstone, ambos da editora Cambridge. A primeira coleção é reconhecida mundialmente ( $3^{a}$ edição), considerada como uma das melhores coleções para o ensino de inglês como língua estrangeira, e será identificada como 'coleção internacional de livro didático 1' - CILD1. A segunda faz parte de uma nova série da editora e será identificada como CILD2.

A CILD1 é formada por quatro volumes, destinados a adolescentes e adultos. Há 16 unidades em cada volume, com um assunto específico em cada. Há um sumário bem dividido e explicativo em cada livro sobre as partes que o compõem. As quatro habilidades linguísticas são abordadas em todas as unidades. A habilidade de leitura corresponde à última parte de cada unidade - é o fechamento. Após a apresentação do texto, são propostas sempre duas ou três atividades referentes ao mesmo. Geralmente, a primeira e a segunda são relacionadas à interpretação, com perguntas ou tarefas bem específicas e facilmente encontradas no corpo do texto. A terceira atividade propõe uma discussão sobre o tema mencionado. O tópico gramatical de cada texto corresponde ao que é trabalhado na unidade; existe uma relação de coerência entre os textos e os aspectos gramaticais em cada unidade.

Nessa coleção, localizamos o tempo verbal presente nas unidades 1 e 2; a primeira unidade para o verbo to be e a segunda para os demais verbos. O tempo verbal passado está presente na unidade 7 e o tempo verbal futuro be going to na unidade 15 . Nas unidades analisadas, encontramos uma diversidade de gêneros, como artigos de revistas, cartões-postais e biografia, além da presença de elementos linguísticos e nãolinguísticos, que auxiliam na compreensão. Entretanto, não encontramos textos autênticos. Poucos são aqueles que contêm fonte, sendo esta, geralmente, incompleta, impossibilitando assim a identificação de onde foi veiculado o texto. A seguir, serão expostas maiores informações (Quadro 3).

Quadro 3 - Análise das seções de leitura (unidades 1, 2, 7 e 15) - coleção Interchange CILD1

\begin{tabular}{|l|l|l|l|l|}
\hline UNIDADE & $\begin{array}{l}\text { TÓPICO } \\
\text { GRAMATICAL }\end{array}$ & $\begin{array}{l}\text { GÊEEROS } \\
\text { DISCURSIVOS } \\
\text { CONTEMPLADOS }\end{array}$ & $\begin{array}{l}\text { AUTENTICIDADE } \\
\text { TEXTUAL }\end{array}$ & $\begin{array}{l}\text { ASPECTOS } \\
\text { OBSERVADOS }\end{array}$ \\
\hline $\begin{array}{l}\text { Unidade } 1 \\
\text { Names } \\
\text { Nacionalidade }\end{array}$ & $\begin{array}{l}\text { Simple Present } \\
\text { Tense }\end{array}$ & $\begin{array}{l}\text { Texto: reportagem } \\
\text { sobre nomes de } \\
\text { pessoas }\end{array}$ & $\begin{array}{l}\text { Texto adaptado - } \\
\text { Sem fonte }\end{array}$ & $\begin{array}{l}\text { Não há presença de } \\
\text { elementos visuais } \\
\text { facilitadores de } \\
\text { compreensão }\end{array}$ \\
\hline$\frac{\text { Unidade } 2}{\text { Profissões }}$ & $\begin{array}{l}\text { Simple Present } \\
\text { Tense }\end{array}$ & Texto: biografias & $\begin{array}{l}\text { Texto adaptado - } \\
\text { Sem fonte }\end{array}$ & $\begin{array}{l}\text { Presença de elementos } \\
\text { visuais facilitadores de } \\
\text { compreensão - fotografia }\end{array}$ \\
\hline $\begin{array}{l}\text { Unidade 07 } \\
\text { Tempo Livre }\end{array}$ & $\begin{array}{l}\text { Simple Past } \\
\text { Tense }\end{array}$ & Texto: cartões-postais & $\begin{array}{l}\text { Texto adaptado - } \\
\text { Sem fonte }\end{array}$ & $\begin{array}{l}\text { Presença de elementos } \\
\text { visuais - fotografia }\end{array}$ \\
\hline $\begin{array}{l}\text { Pnidade } 15 \\
\text { mensagens } e\end{array}$ & Future & $\begin{array}{l}\text { Texto : reportagem } \\
\text { sobre o correto uso do } \\
\text { telefone celular }\end{array}$ & $\begin{array}{l}\text { Texto adaptado de uma } \\
\text { revista sem menção da } \\
\text { fonte }\end{array}$ & $\begin{array}{l}\text { Presença de elementos } \\
\text { visuais facilitadores de } \\
\text { compreensão - gravura }\end{array}$ \\
\hline
\end{tabular}


A CILD2 é também composta por quatro volumes, sendo 12 unidades em cada. Essa coleção é destinada a adultos e adolescentes. Há um sumário bastante detalhado, enfatizando o que será abordado. Todas as unidades possuem a mesma estrutura. São divididas em quatro partes: Lessons $A, B, C$ e $D$, contemplando as quatro habilidades linguísticas. Os autores sugerem que essa ordem de apresentação seja seguida, uma vez que o que é desenvolvido nas primeiras partes serve de requisito para a compreensão das outras, como, por exemplo, vocabulário e estruturas gramaticais.

A habilidade de leitura é desenvolvida na quarta parte. Há questões de pré e pósleitura. Após a exibição do texto, são propostas sempre 1 ou 2 atividades relacionadas à interpretação, com perguntas ou tarefas bem específicas e facilmente encontradas no corpo do texto. O conteúdo gramatical e o tema do texto correspondem ao tópico da unidade. $\mathrm{O}$ texto apresentado serve de subsídio para as atividades de escrita que também fazem parte da Lesson $D$.

Nessa coleção, o tempo verbal presente também é apresentado em duas unidades (unidades 1 e 3), o tempo verbal passado em apenas uma unidade (unidade 5) e o futuro é exposto em duas unidades (unidades 4 e 12). A unidade 4 refere-se à forma gramatical going to e a unidade 12 às formas will, may and might.

Nestas unidades, os textos são adaptações de fontes variadas: jornais, revistas, folhetos e internet, cujos detalhes, como nomes e datas, não são especificados. No material destinado ao professor, isso é mencionado, sendo apenas destacado que esse material fornece um interessante tópico de discussão; o enfoque é dado aos assuntos apresentados. Podem-se verificar maiores informações no quadro a seguir (Quadro 4).

Quadro 4 - Análise das seções de leitura (unidades 1,3,4, 512) - coleção Touchstone CILD2

\begin{tabular}{|c|c|c|c|c|}
\hline UNIDADE & $\begin{array}{l}\text { TÓPICO } \\
\text { GRAMATICAL }\end{array}$ & $\begin{array}{l}\text { GÊNEROS } \\
\text { DISCURSIVOS } \\
\text { CONTEMPLADOS }\end{array}$ & $\begin{array}{l}\text { AUTENTICIDADE } \\
\text { TEXTUAL }\end{array}$ & $\begin{array}{l}\text { ASPECTOS } \\
\text { OBSERVADOS }\end{array}$ \\
\hline$\frac{\text { Unidade } 1}{\text { Amizades }}$ & $\begin{array}{l}\text { Simple Present } \\
\text { Tense }\end{array}$ & $\begin{array}{l}\text { Texto: reportagem } \\
\text { com sugestões para } \\
\text { aprimorar as } \\
\text { habilidades de } \\
\text { comunicação. }\end{array}$ & $\begin{array}{l}\text { Texto adaptado - sem } \\
\text { menção da fonte principal }\end{array}$ & $\begin{array}{l}\text { Presença de elementos } \\
\text { visuais facilitadores de } \\
\text { compreensão - gravuras }\end{array}$ \\
\hline$\frac{\text { Unidade } 3}{\text { Saúde }}$ & $\begin{array}{l}\text { Simple Present } \\
\text { Tense }\end{array}$ & $\begin{array}{l}\text { Texto: folheto } \\
\text { explicativo sobre } \\
\text { saúde }\end{array}$ & $\begin{array}{l}\text { Texto adaptado do } \\
\text { departamento de saúde } \\
\text { americano, sem menção de } \\
\text { data }\end{array}$ & $\begin{array}{l}\text { Presença de elementos } \\
\text { visuais facilitadores de } \\
\text { compreensão - gravuras }\end{array}$ \\
\hline $\begin{array}{l}\text { Unidade } 4 \\
\text { Celebrações } \\
\text { e tradições }\end{array}$ & Future & $\begin{array}{l}\text { Texto: reportagem } \\
\text { sobre tradições em } \\
\text { diversos países }\end{array}$ & Texto adaptado sem fonte & $\begin{array}{l}\text { Presença de elementos } \\
\text { visuais facilitadores de } \\
\text { compreensão - fotografia }\end{array}$ \\
\hline $\begin{array}{l}\text { Unidade } 5 \\
\text { Crescimento }\end{array}$ & $\begin{array}{l}\text { Simple Past } \\
\text { Tense }\end{array}$ & Texto: entrevista & $\begin{array}{l}\text { Texto adaptado de uma } \\
\text { revista, sem menção de } \\
\text { data }\end{array}$ & $\begin{array}{l}\text { Não há presença de } \\
\text { elementos visuais }\end{array}$ \\
\hline $\begin{array}{l}\text { Unidade } 12 \\
\text { Planos, } \\
\text { eventos e } \\
\text { trabalho }\end{array}$ & Future & $\begin{array}{l}\text { Texto: reportagem } \\
\text { sobre a vida no } \\
\text { futuro }\end{array}$ & $\begin{array}{l}\text { Texto adaptado sem } \\
\text { menção da fonte }\end{array}$ & $\begin{array}{l}\text { Presença de elementos } \\
\text { visuais facilitadores de } \\
\text { compreensão - gravuras }\end{array}$ \\
\hline
\end{tabular}




\section{DISCUSSÃO DOS DADOS ENCONTRADOS NAS ANÁLISES}

As coleções brasileiras apresentam, entre elas, características bem distintas quanto à autenticidade dos textos e à diversidade de gêneros textuais, embora ambas façam parte do mesmo programa - o PNLD.

A primeira coleção traz apenas textos autênticos e, desse modo, vem ao encontro do que Holden (2009) chama de contato com a língua viva. Esses textos são extraídos e vinculados a situações reais. Diferentemente da CLD1, a segunda coleção adapta grande parte dos seus textos, a fim de cumprir uma exigência gramatical e, com isso, priva o educador e o educando de terem contato - através do livro - com textos de uso cotidiano, veiculados nos diferentes meios de comunicação. Além disso, ao não se instrumentalizar de um texto autêntico, o livro - a nosso ver - peca em uma das maiores exigências dos PCNs com relação ao ensino de uma língua estrangeira, que é ensinar ao educando/permitir a ele contato com a cultura de outros povos, os quais falam esse outro idioma. $O$ ensino apenas de formas estáticas e a aquisição de estruturas linguísticas prontas não é uma das diretrizes dos PCNs. O que os PCNs reforçam é a necessidade de uma formação integral ao educando, a qual inclua o aspecto cultural.

Ainda nesse ponto de vista, importa não só a autenticidade, mas também a diversidade de gêneros apresentada nos textos dos LD. Apreender determinado gênero de uma língua estrangeira é apreender aspectos sócio-históricos e culturais que envolvem essa língua (BENTES, 2005). Ambas as coleções nacionais apresentam certa diversidade de gêneros, mas há uma predominância daqueles que apresentam conteúdo informativo.

No que tange às coleções internacionais, a variabilidade em relação à autenticidade dos textos não é muito diferente da apresentada na CLD2, isto é, não seguem um padrão de texto autêntico, apresentando textos adaptados. O que ocorre é que muitos dos textos não possuem fonte, ou a apresentam de forma incompleta, dificultando, assim, a identificação do meio o qual produziu e veiculou esse texto.

Percebemos que nessas coleções internacionais, embora a habilidade de leitura seja trabalhada, a ênfase se dá no desenvolvimento das habilidades comunicativas. Entretanto, ainda que o desenvolvimento da habilidade de leitura não seja o foco das coleções internacionais analisadas, verificamos que há uma diversidade de gêneros textuais, como entrevistas, artigos de jornais e revistas, folhetos explicativos, com o predomínio de textos informativos, levando o leitor a conhecer a estrutura gramatical da língua alvo e seu vocabulário, bem como a promover tópicos de discussões.

Através da apresentação de gêneros variados, o LD permite que se possa ter contato com aspectos culturais e sociais da língua aprendida, o que não deve jamais ser desconsiderado, uma vez que aprender um novo idioma remete ao aprendizado das formas de organização social, cultural e políticas de uma nação. Resta salientar que tal contato só não ocorre de forma eficiente caso o gênero seja abordado com conteúdo não autêntico, como é o caso das coleções CILD 1 e 2.

\section{CONSIDERAÇÕES FINAIS}

No que tange aos aspectos observados nas análises dos livros didáticos, pode-se verificar que em textos adaptados e sem fonte parece ter havido uma maior preocupação com o tópico gramatical e a possibilidade de interação entre aprendizes e professor a partir do tema do texto. Por outro lado, em textos autênticos pode-se observar, além de 
questões gramaticais, uma maior preocupação na formação do leitor e em proporcionar o contato com a língua real. Todos os livros didáticos, sejam nacionais ou estrangeiros, parecem pecar no quesito autenticidade textual, pois, das quatro coleções analisadas, apenas uma delas - a de origem nacional - apresentou totalidade de textos autênticos.

Atinente à diversidade de gênero, a preocupação - por parte dos autores e organizadores dos livros - parece ter sido um pouco maior do que com a autenticidade textual. Constatamos que as quatro coleções analisadas apresentam textos com alguma diversidade, mesmo havendo predominância de um gênero sobre os outros. Entretanto, verificamos que a oferta de textos de tipos variados ocorre como uma forma de propiciar temas de discussão e interação entre alunos, afora o conhecimento da estrutura da língua. $\mathrm{O}$ conhecimento dos aspectos sócio-culturais e históricos que envolvem a língua aprendida aparece como algo secundário, de acordo com nossa análise.

Com base nos dados encontrados no material pesquisado, é possível pôr em discussão que o ensino atual de língua estrangeira no Brasil parece ainda estar mais voltado para o aspecto formal - isto é, voltado ao trabalho do texto como pretexto, enfatizando-se questões gramaticais - em detrimento de um trabalho, apesar de reforçar os PCNs, mais voltado para o aspecto cultural do outro idioma. No âmbito internacional, o resultado não é diferente.

Parece, assim, que os autores dos livros didáticos analisados neste artigo mostram certa sensibilidade e comprometimento com a diversidade de gênero; no entanto, não demonstram igual compromisso com a autenticidade dos mesmos. Ao mesmo tempo, os elementos que denotam expressão da língua viva não são explorados nos textos, ficando, desse modo, em segundo plano. É preciso haver uma unidade entre ambas essas características para que o material fique mais completo e possa oferecer contato com o idioma em uso real e, ao mesmo tempo, com a outra cultura. Portanto, tanto autenticidade textual quanto diversidade de gênero se mostram características indispensáveis no desenvolvimento da habilidade linguística da leitura.

\section{REFERÊNCIAS}

AUN, Eliana; MORAIES, Maria Clara; SANSANOVICZ, Neuza. English for all. São Paulo: Saraiva, 2010.

BRASIL. Ministério da Educação, Secretaria de Educação Fundamental. Parâmetros Curriculares Nacionais: Língua Estrangeira - Terceiro e Quarto Ciclos do Ensino Fundamental. v. 2. Brasília, DF: MEC, 1998.

BAKHTIN, Mikhail. Os gêneros do discurso (1952-1953). In: Estética da criação verbal [1979]. Trad. Paulo Bezerra. 4. ed. São Paulo: Martins Fontes, 2003.

BENTES, Anna Christina. Gênero e ensino: algumas reflexões sobre a produção de materiais didáticos para a educação de jovens e adultos. In: Gêneros textuais: reflexões e ensino. KARWOSKI, Acir Mário; GAYDECZKA, Beatriz; BRITO, Karim Siebeneicher (Orgs.). Palmas e União da Vitória: Kaygangue, 2005. 
BUNZEN, Clecio; ROJO, Roxane. Livro didático de língua portuguesa: autoria e estilo. In: VAL, M. da G.; MARCUSCHI, B. Livros didáticos de língua portuguesa: letramento e cidadania. Belo Horizonte: CEALE/Autêntica, 2005.

HOLDEN, Susan. O ensino da Língua Inglesa nos dias atuais. São Paulo: Macmillan, 2009.

LEFFA, Vilson. Perspectivas no estudo da leitura: texto, leitor e interação social. In: LEFFA, Vilson; PEREIRA Aracy. O ensino da leitura e produção textual: alternativas de renovação. Pelotas: Educat, 1999.

MARQUES, Amadeu. On Stage. São Paulo: Ática, 2011.

MARCUSCHI, Luiz Antônio. Produção textual, análise de gêneros e compreensão. São Paulo: Parábola Editorial, 2008.

MCCARTHY, Michael; MCCARTEM, Jeanne; SANDIFORD, Helen. Touchstone. New York: Cambridge University Press, 2005.

MISHAN, F. Designing Authenticity into Language Learning Materials. UK: Intellect Books, 2005.

RICHARDS, Jack; HULL, Jonathan; PROCTOR, Susan. Interchange. New York: Cambridge University Press, 2005.

SANTOS, Clara Carolina; TOMITCH, Leda. Aquisição de leitura em Língua Inglesa. In: DIÓGENES, Cândido. Ensino e aprendizagem de língua inglesa: conversas com especialistas. São Paulo: Parábola, 2009.

SCHUBERT, Bianca Pimentel. A autenticidade do material didático para o ensino de inglês como língua estrangeira. Linguagens e Diálogos, v. 1, n. 2, p. 1-16, 2010.

Recebido em: 05/11/2012

Aceito em: 18/04/2013

Versão revisada recebida em: 06/05/2013

Publicado em: 14/06/2013

\title{
DISCURSIVE GENDER AND TEXTUAL AUTENTICITY IN FOREING LANGUAGE TEACHING: AN ANALYSIS OF TEXTBOOKS
}

\begin{abstract}
Choosing an appropriate textbook for the real needs of students is a very important subject and, at the same time, it is one of the biggest challenges for foreign language teachers. Regarding foreign language teaching and learning process, we highlight two aspects: textual authenticity and diversity of discursive genders. Discussing about these features, we selected four textbooks collections, which were edited after 2004. Two collections were produced in Brazil and two were elaborated in countries where English is a mother tongue. We focus our analysis on units that bring up present, past and future tenses of verbs. We follow the Bakhtinian theoretical conceptions. In this view, the discourse has a dialogic nature and is organized by discursive genre in a social field. In this paper, we aim to promote a discussion about these topics and to offer support for foreign language teaching and learning.
\end{abstract}

KEYWORDS: foreign language teaching; discursive genre; textual authenticity. 